\title{
Familiarity as a practical sense of place
}

\author{
Maxime Felder*
}

* Laboratory of Urban Sociology, EPFL-Swiss Federal Institute of Technology Lausanne, 1015 Lausanne, Switzerland. Email: maxime.felder@epfl.ch

\section{--- Preprint ---}

Published version:

Felder, M. (2021) Familiarity as a practical sense of place. Sociological Theory, 39(3). https://doi.org/10.1177/07352751211037724 


\title{
Familiarity as a practical sense of place
}

\begin{abstract}
Familiarity is an elusive concept, capturing what we know intimately and what we only recognize from having seen before. This article aims to disambiguate these interpretations by proposing a sociological conceptualization of familiarity as a dynamic relationship to the world that develops over time and through experience, and that allows one to progressively disattend from what appears as "usual." Focusing on how urban environments and their human entities become familiar and stop being familiar, I propose that familiarity be thought of as an ongoing relational and interactional achievement, allowing us to focus on our daily activities while relying on a practical knowledge of our surroundings. The conceptualization process unfolds via five questions: What is familiarity? Where does it come from? What threatens it? What does it produce? How can it be operationalized and studied empirically?
\end{abstract}

Familiarity poses a challenge for social scientists. Depending on their relation to their object of study, researchers face the task of either making the strange familiar or making the familiar strange. In the first process, researchers seek to acquire familiarity through repeated encounters with something unknown to them (i.e., the anthropological tradition). Within the second process, however, familiarity constitutes an obstacle to overcome. Researchers already familiar with their object of research seek to break away from the taken-for granted knowledge associated with it.

This pair of precepts points to the ambiguity of familiarity: it refers both to knowing well and knowing superficially. I claim this is not a contradiction and that familiarity combines both modes of knowing. More than a type of knowledge, familiarity appears as a relationship to the world that develops over time and through experience, and that allows one to progressively disattend from what appears as "usual." Such a relationship remains fragile and can be broken, in a gradual or sudden way, intentionally or not. In this article, I consider the question of how to conceptualize this relationship sociologically. Focusing on how urban environments and their human entities become familiar and stop being familiar, I propose that familiarity be thought of as an ongoing relational achievement that allows us to focus on our daily activities while relying on an embodied, practical, yet superficial knowledge of our surroundings.

Cities, because of their size and complexity, are sometimes considered unknowable places of anonymity. If so, could familiarity explain how city dwellers nevertheless find their way around and feel at ease in the city? As a means of handling the public realm, familiarity emerges as an 


\section{--- Preprint ---}

alternative to domestication or privatization, or retreat into the home (Kumar and Makarova 2008). Furthermore, exploring familiarity may help us understand how we organize our "outings" (DeLand and Trouille 2018), why we often stick to routines, and how we choose certain routes and locations while avoiding others.

This article explores five aspects of familiarity. I begin by defining familiarity as a practical sense of place. As an embodied understanding, it cannot be reduced to a quantity of knowledge, nor be placed on a continuum between a weak and a strong sense of place, or positive and negative relationship with place. Second, I turn to the conditions that facilitate the emergence of familiarization. I discuss the characteristics of this learning process and ask why it does not leadcontrary to what we might expect- to ever deeper knowledge. This process is often presented in its individual, cognitive dimensions, but I emphasize its relational dimension: familiarity is a collective achievement. Third, I ask what threatens familiarity. Unexpected events and changes in an environment can be triggers, but can defamiliarization result from changes in the way we perceive and engage with our surroundings? I also evaluate the conditions that prevent one from developing familiarity. Fourth, what are the consequences of familiarity? If familiarity can induce trust, can it also be a source of distrust? And if it can lead to a sense of belonging, can it also give rise to boredom and entrapment? Finally, I look at the ways familiarity can be operationalized and studied empirically.

I draw on ethnographic research in which scholars describe how city dwellers manage and navigate their environments and how they get to know "familiar strangers." I build on the literature on individuals' relationships with their environments and the literature on interpersonal relationships, shedding light on familiarization from two angles. This article also draws on interviews I conducted in 2015 and 2016 in Geneva, Switzerland, in which I asked residents of four buildings located in the city center about their use and experience of the city, their neighborhood, and their neighbor relations.

\section{WHAT IS FAMILIARITY?}

The Oxford English Dictionary defines familiarity as the state of knowing somebody/something well and the state of recognizing somebody/something. As with the anthropological precepts that open this article, these definitions signal an ambiguity at the heart of the notion: the adjective familiar applies both to what is known well and to what is known superficially. This ambiguity results in very different uses of the term.

The most common use simply contrasts the familiar with the unfamiliar, the strange or the unknown. Consider the first paragraph of Street Corner Society. Whyte (1943:xv) explains that “Cornerville is only a few minutes' walk from fashionable High Street, but the High Street inhabitant who takes that walk passes from the familiar to the unknown." Here, the meaning of familiar comes close to known and is sometimes used with a qualifier, to mark varying degrees, from the least to the most familiar. 
French sociologist Laurent Thévenot (2007:416) takes a different approach to the idea of familiarity and contrasts "the intimacy of the familiar"-defined as a deeply personal way of apprehending reality - with standard and common forms of knowledge. There is no mention of degrees here. Everything that is known in this "cognitive format" is considered familiar, from the camera whose every button we master (Thévenot 1994) to our home, where "the things we appropriate are customized, tamed, or domesticated" (Thévenot 2001:69).

Drawing on Blokland (2003, 2017), I develop a third approach. Taking up Fischer's (1982) notion of "public familiarity," Blokland offers an intermediate reading of urban sociality that circumvents the opposition between two ideal-types: the anonymous, modern city and the urban village. She opens the way for a conceptualization of familiarity as practical knowledge acquired through routines and as a collective practice, akin to Goffman's civil inattention. I aim to extend this approach by leveraging phenomenological literature, first to shed light on the forms of knowledge underpinning familiarity, and then to reveal its sensory and embodied character.

\section{The contours of familiarity}

From a phenomenological perspective, our whole "everyday life-world" can be said to be familiar, since we take it for granted as "reality" (Schütz and Luckmann 1973:3). Existing, or "being-in-theworld," already implies a basic familiarity with things that are "at hand" (Heidegger 2010 [1927]). This reality we take for granted, however, is made of different types of knowledge.

Familiarity consists of two main layers. The base layer gathers a stock of knowledge from which we operate. Schütz and Luckman (1973:146) call this "typification": "new experiences can be determined with the help of a type constituted in prior experiences." This operation largely accounts for the "basic familiarity" described by phenomenologists. Indeed, something or someone we meet for the first time rarely appears completely unfamiliar to us. In a new city, a visitor can usually distinguish the pavement from the sidewalk, so as not to be hit by a car, and might also be able to identify different types of neighborhoods.

Whereas this first layer allows us to grasp as "similar" what we have already encountered elsewhere, the second layer allows us to recognize objects and experiences as "the same" (Schütz and Luckmann 1973:229). This first-hand knowledge applies to specific objects, individuals, and situations. These are known not only from types, however detailed and personal they may be, but in their individuality. The first layer allows us to manage most situations, but it does not provide the same ease as the second layer, especially with respect to potential risks. For example, to carry out a postal worker's activities with ease, one may not be satisfied with recognizing dogs from other animals, or even with identifying different breeds of dogs. Rather, the postal worker must distinguish between neighborhood dogs that bite versus those that do not bite. This example, borrowed from Schütz, points to knowledge acquired in situ, which is not driven by an interest in dogs but by a specific motivation: not to be bitten.

Focusing on familiarity in encounters with others helps further distinguish the two layers. Meeting someone in my neighborhood whom I recognize as a jogger from their clothes does not provide 
the same experience of feeling "at home" as recognizing a jogger whom I regularly encounter on my daily walks. The latter is what Milgram calls a "familiar stranger": someone who is not known "categorically" but "personally" (on this distinction, see Lofland 1973:15-19). A familiar stranger is recognized by some unique characteristics and is not interchangeable. Meeting a random jogger is only an interaction, whereas the familiar jogger provides a fully-fledged, lasting social relationship. More than that of typification, this second layer of familiarity has a relational dimension. As I will discuss, when we acquire first-hand knowledge, we inhabit places and mark them with our repeated presence: we treat others as familiar presences and potentially become familiar presences to others.

This first-hand knowledge is nonetheless superficial. The familiar stranger remains a stranger, and the familiar environment retains some strangeness. Consequently, saying we feel "at home" in a familiar place can only be a metaphor. The knowledge we have of the places we routinely frequent is characterized by specific limitations that do not apply to the knowledge of our home. What is known just well enough to carry out daily activities is also ignored in many respects.

Consider the route one takes to get to the subway. The first time you went, you may have consulted a map or asked for directions. A few days later, you were able to find your way without too much difficulty. A few months later, you have taken this route dozens of times and can reach the station without any difficulty, even while caught up in a conversation. If one keeps this routine, we can assume that years later, our knowledge of the area will have barely increased. Once the surroundings become familiar, unless something draws our attention, we can stop focusing on them and instead concentrate on our daily activities.

Familiarity relies on knowledge that is only loosely thematized. It is acquired while we are busy doing other things and our attention is focused elsewhere. Consider a tourist taking the same route to the subway. With a camera in her hand, she walks slowly and observes building facades she finds eye-catching. The visit provides her with what Polanyi calls focal knowledge, which he describes as "knowing by attending to." In contrast, routines provide "subsidiary knowledge," which implies "knowing by relying on our awareness of it for the purpose of attending to something else" (Polanyi 1962:601). This subsidiary and practical dimension distinguishes familiarity from other forms of intermediate knowledge. As a result, what is familiar is not what we do not yet know well, but rather what we know well enough so we no longer pay much attention to it, thus preventing us from getting to know it better.

\section{A practical sense of place}

Such knowledge leads to grasping a setting as a whole, while disattending from its particulars. As Merleau-Ponty (2005:374) notes, what is perceived

\footnotetext{
"is not necessarily an object present before me as a piece of knowledge to be acquired, it may be a 'unity of value' which is present to me only practically. If a picture has been removed from a living room, we may perceive that a change has taken place without being able to say what."
}

A simple deviation from the ordinary can be destabilizing and force us to disengage from autopilot. 
This way of looking nonetheless spares our attention; it permits us to assess at a glance whether appearances are "normal" (Goffman 1971:283). Because places are being experienced rather than "pregiven" (Casey 2009), the notion of "normal appearances" could be extended to "normal experiences." As a consequence, what is familiar is not so much the place or the person itself, with its supposedly intrinsic qualities we memorize, as a positivistic approach would suggest. Rather, it is the perception of how are presented to us practically.

Consider a situation in which we always walk to the subway station in the morning, and a colleague drives us home in the evening. One day this colleague is absent, so in the evening we have to walk the usual road but, for the first time, in the opposite direction. The surroundings may no longer seem familiar. They may appear in a new light, literally, and be less recognizable from the new orientation. The elements composing the scene remain the same, but we perceive them in a different order. Some elements may simply have disappeared — such as a landmark we are used to seeing in the background - and others that were hidden are now visible. For example, billboards we could only see from behind suddenly appear as if they had just been installed.

Instead of a process of memorization through repetition, familiarization should thus be viewed as a process of regularly experiencing an environment in a particular way, to the point where we take the experience for granted. This experience is not that of a detached observer but of an "embodied mind" (Gallagher and Zahavi 2020). It is informed by a body and its senses. The "normal experience" includes not only the familiar landscape but also a soundscape (Cogger 2016) and even a smellscape (Henshaw 2014) that have become so usual we barely notice them. These sensory experiences, progressively "sedimented" (Merleau-Ponty 2005) in our stock of knowledge, provide an embodied understanding of familiar places. ${ }^{1}$ The notion of a practical sense of place (Relph 2008) accounts for both the subsidiary dimension of this understanding and its sensory, embodied character.

As a sense of place, familiarity cannot easily be defined in terms of strength or valence (as being either positive or negative), as some authors approach relation to places (Shamai and Ilatov 2005). The sense of ease familiarity provides relates to the conduct of daily activities, not necessarily to the place itself. People familiar with a place may or may not like it (Blokland and Nast 2014). In fact, because a place is no longer the focus of attention once it becomes familiar, the relationship may well be neutral.

Instead of its strength or valence, what makes familiarity distinct is its practical dimension: familiarity is acquired hands-on, through routine, while attending to everyday life. As with other characteristics I have described, this practicality relates to the way familiarity is created. To better understand familiarity, it is therefore necessary to look at the conditions and processes that facilitate its emergence. 


\section{WHERE DOES FAMILIARITY COME FROM?}

Familiarity comes from a learning process that can be described as familiarization. As stated earlier, this process involves practical learning. First, factors such as regularity of practices and stability of the environment facilitate the emergence of familiarity, but familiarity is not an inevitable result of routines. Second, familiarity not only results from a pre-reflexive corporeal learning process, but it may also involve inductive reasoning when specific problems arise. Third, familiarization as a learning process does not, paradoxically, lead to ever more complete knowledge. Finally, viewing familiarization as more than a cognitive process entails highlighting its collective and relational dimensions.

\section{Repetition and stability}

The role of repetition in familiarization is key. Although it is possible to become intimate with someone in the course of a single long conversation (Lofland 1973:19), familiar knowledge is acquired over time through repeated exposure. Information is collected through recurring fleeting encounters and direct observation, sometimes supplemented by indirect sources (e.g., gossip [Felder 2016, 2019]). The other is known personally yet remains a stranger due to lack of personal information, uncertainty regarding the acquired information, and lack of interest in probing the matter.

Similarly, an environment becomes familiar through regular use. Habits, but also rules and norms, result in "the conversion of public space into a patterned ground that proves essential for actors to make sense of the space, their place within it and their way through it" (Amin 2008:12). At a collective level, these patterns translate into regular paths, and spatial and temporal points of intersection, in which people's trajectories regularly diverge and intersect. These phenomena are enabled by the relative stability of our living places, work routines, leisure practices, and our use of time (Vagni and Cornwell 2018). People who are regularly forced to change their routines are probably pushed into other types of learning.

Even the most routine practices would not allow for familiarization in an environment in perpetual transformation. Familiarity does not presuppose complete stability-a city is constantly changing - but a pace of transformation that is slow enough for changes to be assimilated. The familiarization process requires regularly updating our stock of knowledge. This can be done incrementally when minor changes occur. A freshly repainted building does not prevent us from recognizing our street. However, a situation may be sufficiently unexpected and problematic that it must be addressed and solved through trial-and-error learning.

\section{Trial-and-error learning}

A certain stability of the material environment is expected, but this is less the case with the human environment. However, although we do not expect to meet the same people on the street every day, we do expect people to behave in certain ways in certain situations, and we learn to adjust our behavior accordingly. Familiarization thus involves learning the "code," as Anderson (2000:36) 
put it: this code allows us to "know what time it is ... not by the clock but by reading people, places, and situations [which allows one to] grasp the public signals of what is yet to come." In his study of Philadelphia inner-city neighborhoods, Anderson (2000:145) shows that "as children learn to deal with their social environment, they may thus quickly put aside the lessons of the home." The problem lies not so much in parents' lessons, as in the limits of what can be taught. Learning the rules of an environment requires hands-on trial-and-error learning.

Take Sonia's unexpected encounter with drug dealers (Felder and Pignolo 2018). Sonia was 40 years old and had been looking for work since she lost her job as a secretary. After she moved into the neighborhood, she realized drug dealers were routinely hanging out in front of her building:

At first it upset me because there are schools around here, but then I said to myself "no" . . [ [the fact that drug dealers work here] doesn't mean the kids have become drug addicts. And the dealers are not stupid. ... Finally, I started to like them because they were already respectful with me. I think they know that I live in the neighborhood. They never assaulted me, nor offered [drugs] to me.... Sometimes they say hello and I have always answered them politely.

The process Sonia described consists of inductive reasoning based on her observations and her repeated interactions with the dealers, leading her to reconsider her initial judgment. Sonia's relation to the dealers is not trouble-free, but she no longer experiences the distressing uncertainty that characterized her first few months in her apartment. Her explanation in the above quote serves as a satisfactory temporary solution, allowing her to continue her daily life.

Sonia's case illustrates a form of normalization that "make[s] the strange actions intelligible and . .. restore[s] the situation to normal appearances" (Garfinkel 1984:47). However, the process was interrupted as soon as "what was questionable became explicated, the problem solved - in a manner and to a degree that was sufficient for the actual, situationally conditioned problematic" (Schütz and Luckmann 1973:13).

In the first few months, Sonia tried to determine whether she should fear the drug dealers, but this learning process was quickly put on hold once she found a satisfactory answer. Six years later, she did not know any more about these people, not their names, where they came from, or even if they were really selling drugs. She was satisfied with this limited knowledge that allowed her to come and go from her home without further questioning.

The existence of plateaus in learning curves is debated, but examples suggest learning curves sometimes start steep then rapidly level out and become almost flat, despite practice and experience (Speelman and Kirsner 2005:28-29). The process of familiarization follows such a curve: the people I meet regularly on my street may become familiar strangers after a few weeks, but I may continue to meet them for years without getting to know them any better. In a similar fashion, once an environment becomes familiar, it is wallpaper that - in typical situations and unless we have a particular interest - is no longer given much attention. 


\section{A collective achievement}

Familiarity is often seen as "one's own achievement" (Casey 2000:407), resulting from cognitive processes (for neuroscientists and psychologists) or perceptual processes (for phenomenological philosophers). However, more than an individual endeavor, familiarity is a collective achievement. It requires forms of tacit coordination that underlie "normal experiences" and endow urban life with some predictability.

Sonia's story shows how individuals contribute collectively to making familiarity possible by enacting what Goffman (1971:282) calls "a normalcy show, a show in which all participants have the task of acting unfurtively." Here, it involved Sonia curbing her disapproval and treating the dealers as "good neighbors" (Rosenblum 2016). Beyond the trial-and-error process through which she concluded, provisionally, that they were not a threat, the anticipation of future encounters probably compelled her to prioritize the smoothness of their interactions. As for the drug dealers, the "normalcy show" was essential to the continuity of their business. Residents, and to some extent the police, turned a blind eye as long as the dealers did not disturb the "normal experience" of the neighborhood too much (Felder and Pignolo 2018; Rodgers 2020).

There are, of course, other reasons to participate in the interaction order that are not strategic (Rawls 1987). However, what is critical for our purpose is that familiarity emerges from a collective construction of normality that mitigates the "arbitrary character of reality" (Misztal 2015:50) and ensures a certain predictability and appearance of normality. This underlines the relational character of places that are continuously produced and reproduced by human practices. Stability "is the emergent and always provisional outcome of successively faithful reproductions of practice" (Shove, Pantzar, and Watson 2012:13).

The phenomenon of familiar strangers thus relies not only on the regularity of practices in time and space, which allows for the repetition of encounters, but also on a shared commitment not to push the relationship toward more intimacy. As we will see in the next section, breaking the familiar relationship would only require one of the two people to cross the line - for example, by starting a personal conversation instead of sticking to a perfunctory greeting.

Even if actors commit to their alignment, disruptions are unavoidable. As Tavory and Fine (2020) argue, rather than failures, disruptions can be seen as resources for negotiating relationships and revising our definition of a situation. In the drug dealers' case, the normality on which familiarity emerged was not a stable order, but a succession of disruptions and alignments. In fact, the relationship between the residents and the dealers was punctuated by moments of crisis, such as when the dealers were seen hanging out in the schoolyard (Felder and Pignolo 2018). Their subsequent understanding of the disruption they had produced and their return to their usual spot restored a sense of familiarity, at least from the residents' point of view. In this case, the breach contributed to the production of intersubjectivity (Tavory and Fine 2020). However, the alignment was not symmetrical. Depending on their position in the balance of power, individuals must make 
more or less effort and are more or less forced into revising their understanding of the situation to ensure the "normalcy show."

Familiarity thus emerges from a learning process that involves moments of negotiation and adjustment - often without verbal communication - during which people try to find a modus vivendi. When they succeed, a self-reinforcing dynamic appears. The fact that other people behave routinely in environments that feel familiar to them helps us develop a familiar relationship with that environment. However, even if we are able to overcome and learn from temporary breaches, some breaches lead to a relational rupture (Tavory and Fine 2020). Familiarity seems to be "an unavoidable fact of life" (Luhmann 2000:95), and strangeness cannot be a permanent state (Haapala 2005), but familiarity remains fragile.

\section{WHAT THREATENS FAMILIARITY?}

If repetition and stability underpin familiarity, change and uncertainty threaten it. Unsettling events may shatter what we take for granted, and threats may engender permanent vigilance. Change may come from the environment, but defamiliarization may also have to do with how we perceive and experience it, as when we feel "out of place." Breaking with familiarity, however, not only leads to a state of anxiety and uncertainty, but it can also be the prelude to a new learning process, as in the case of the researcher who uses defamiliarization as a heuristic tool.

\section{Change as a trigger for defamiliarization}

Although all environments change gradually, transformation may be too fast, too drastic, or too symbolic, so the dynamic process of familiarization is overwhelmed. Witnessing or being the victim of an assault or terrorist act deeply violates our sense of predictability (Blokland 2017), but more subtle events may also be unsettling. The demolition of a building or the closure of a café can disrupt familiarity (Haapala 2005; Lofland 1998:67) even in cases where we are unable to say exactly what has changed.

In the same way, a familiar stranger's disappearance can act as a trigger. Most residents of one of the residential buildings I studied were familiar with an elderly woman who rarely left her home and who watched television with the volume turned up so high the program could be followed from the stairwell. One summer's day, she was gone. The disappearance caused concern even among people who had no interaction with her and probably did not know her name. A well-informed neighbor could tell them she had moved to a nursing home.

On the one hand, this example emphasizes the emotional significance of familiarity and the fact that it goes unnoticed until it is no longer there. On the other hand, it points to the difficulty in capturing this relationship — whether to a place or a person — using the usual indicators of tie strength (Marsden and Campbell 2012). A tie to a familiar stranger is not necessarily reciprocal, it involves no closeness or intimacy, no interaction or resource flow, and the emotional attachment may remain imperceptible to the actors. This is why I call interpersonal ties invisible (Felder 2020). Their existence sometimes only becomes manifest when they are broken. 
Defamiliarization is not always sudden, however, and does not always have exogenous causes. In the earlier example concerning the journey to the subway station, a simple change of habit (making the journey in an unusual direction, at an unusual time) can be disruptive. Furthermore, defamiliarization can translate as a failure to keep pace with the transformations around us. Among the oldest residents I interviewed, some had been living in the same apartment for more than $\mathbf{5 0}$ years. Yet their environment did not always feel familiar to them. The turnover in their building combined with their advancement in age complicated the continuous process of (re)familiarization. For instance, by leaving home less often, the chance of running into neighbors decreases and thus the latter gradually stop being familiar strangers.

Aging involves a disruption to routines, which may result in a sense of estrangement from the world (Riom, Hummel, and Burton-Jeangros 2018). As some aging people lose their "ability to act in, engage with and be in the world ... [they experience] shrinking zones of comfortable movement" (May and Muir 2015:6). Familiarity with a place may thus increase over time and then decline with deteriorating cognitive and physical functioning (Burns, Lavoie, and Rose 2012). Other scholars have challenged an "impairment-led" explanation for the experience of a "shrinking world": people with dementia, they argue, recreate their neighborhood through habitual practices, concentrating more time in certain places, allowing them to "hold on to familiarity" (Ward et al. 2021:9). These people are not prevented from developing familiar relationships altogether, but the space for doing so has been reduced. Such restrictions also affect people who feel threatened or believe they simply do not fit in.

\section{Feeling threatened or "out of place"}

Analyzing migrant illegality in Israel, Willen (2007:9) met Kofi, a Ghanaian man:

"He was always on guard . . . always looking around, always keeping eyes and ears open for the distinctive light-blue shirts of uniformed police or for cops in civilian clothing. When walking down the street, particularly in areas known to be 'hot,' Kofi would stay alert, always ready to duck down an alley or side street." For Kofi, taking the same road and waiting for the bus at the same stop every day did not generate a feeling of ease; far from it.

Enacting familiarity means letting one's guard down, which individuals who live under constant threat of arrest or violence cannot afford to do. For Kofi, continuously improving his knowledge of the area, being able to spot, for example, plain-clothed police officers, was a matter of survival. McFarlane's (2011) description of a train station in Mumbai provides another valuable example. Unlike travelers who know the station just well enough to find their way around with limited concern, children living in the train station under constant threat of police repression know the station like the back of their hand. The regular traveler's familiarity contrasts with the children's intimate knowledge of the station.

These cases may seem extreme, but depending on the context, being a woman, having a disability, being Black, being LGBTQ, or wearing a veil is enough to prevent development of a familiar relationship with one's environment. Instead of appearing as a whole, for people who are constantly 
under threat or surveilled, one's surroundings may appear as a collection of potentially dangerous elements that must be evaluated with care.

Even feeling "out of place" may be enough to prevent the emergence of familiarity. This feeling can be provoked by a stare or by a friendly "Can I help you?"- -both subtle forms of social control (Blokland 2017:70). Such a "proprietary attitude"—Lofland's term for "acting the host"—results in a form of privatization that can be exclusionary. However, the sheer size of a group may translate as a form of "colonization." In sufficient numbers, elderly women can "take over" a cafeteria, as Lofland (1973:125-28) illustrates.

Familiarity is made easier for individuals who navigate through places that have been shaped for them by historical processes, but places are also shaped by the current presence of certain people and the absence of others. Ahmed (2007:161) explains how "spaces acquire the shape of the bodies that 'inhabit' them ... spaces 'record' the repetition of acts, and the 'passing by' of some and not others." Therefore, in "white spaces," some bodies just "flow into space," while others attract attention as soon as they arrive: the noticeability of someone's arrival already implies that it causes disorientation (Ahmed 2007:161).

A person's failure to develop a familiar relationship with a place is not always due to others preventing them from doing so. One can imagine being fascinated by a place to the point where knowing it in a subsidiary way is not an option. In the case of a place one loves, each visit is an opportunity to discover a new aspect of its charm. Conversely, aversion to a place may cause one to notice a new flaw upon every occasion there. People may even actively seek not to develop a familiar relationship, to distance themselves and emphasize their non-belonging.

Finally, one may avoid becoming familiar for specific purposes. Consider a painter trying to depict a street scene, a police officer patrolling a neighborhood, or a sociologist doing fieldwork. Not only can they not afford to disattend from the environment and be satisfied with "subsidiary knowledge," but their activity necessarily leads them to develop "focal knowledge" (Polanyi 1962). The sociologist, for example, will seek to overcome the superficiality of familiarity by not taking appearances for granted, and not being satisfied with one standpoint and the typical situation, but rather being concerned with "intersituational variations" (Trouille and Tavory 2019). As stated earlier, "estranging the familiar" to shed light on "[o]bjects that were relegated to the background of our experience" (Timmermans and Tavory 2012:177) requires effort that most people do not extend during their busy days, unless change is forced upon them, placing them in a vulnerable position. Like the researcher, the person forced to become "streetwise" has to engage in "field research" (Anderson 1990:230).

Defamiliarization may seem like a return to a state of ignorance and uncertainty, but the examples provided here show the opposite is true. The person living under potential threat, the police officer and the sociologist are in fact pushed toward another form of knowledge. However, while the police officer and the sociologist may use defamiliarization as an opportunity, others may experience it as a constraint that reinforces their vulnerable state. The consequences of not being in a position to 
develop a familiar relationship with one's environment become clearer by analyzing what familiarity produces or allows.

\section{WHAT DOES FAMILIARITY PRODUCE?}

I will explore two types of outcome: a feeling of ease, enabled by the capacity to know what to expect, and who and when to trust or distrust (Blokland 2017), and attachments that may or may not turn into a sense of belonging. However, fully grasping what familiarity produces requires considering not only the point of view of the central person, but also the perspective of those whom they cross paths with. Familiarity is almost always seen in a positive light, but this relational perspective reveals ambiguities. I conclude by considering the possibility of an "overfamiliarity."

\section{Ease and discomfort, trust and distrust}

In the wake of Titchener (1914), who noticed the "glow of warmth" people experience in the presence of familiar things, psychologists like Zajonc (1968:23) demonstrated that "mere repeated exposure of an individual to a stimulus object enhances his attitude toward it." No single mechanism can explain the influence of exposure on attitudes (Lee 2001), but in the case of urban environments, one possible explanation involves the ease provided by having a practical sense of place. Blokland and Nast (2014:1145) argue that familiarity results in "comfort zones," where one does not need to make an effort, or actively "work things out," and above all where one is "able to assess what to expect."

However, because this ability is based on largely tacit knowledge, we may not be able to articulate what we expect. Moreover, experience may contradict our expectations. This ability to develop expectations thus makes one vulnerable to unforeseen changes: the closing of a long-standing café troubles only the familiar person; the person passing by for the first time sees nothing but a closed café. Consequently, familiarity produces a sense of comfort when "everything seems in proper order" (Lewis and Weigert 1985:974), but it is also responsible for a sense of discomfort when this order appears disrupted.

In fact, "to hold some expectations about something future or contingent or to have some belief as to how another person will perform on some future occasion" is nothing more than a definition of trust (Misztal 1996:24). Applying the same logic leads us to consider that rather than delivering trust, familiarity helps us overcome distrust, which Sztompka (1999:26) defines as "a lack of clear expectations . . . a neutral situation, when both trust and distrust are suspended." Based on an inductive process in which we extrapolate from our experiences and the available evidence, we learn to discriminate among people, places, and situations we trust and those we distrust. Trust is thus inseparable from its negative mirror image: distrust (Sztompka 1999:26).

During her fieldwork in a disadvantaged area of Rotterdam, one of Blokland's (2011) interviewees explained that in her neighborhood, the gangsters do not scare her. In an unfamiliar neighborhood, 
however, she remains watchful. "Put briefly and therefore too crudely," Blokland (2011:192) writes, "we feel unsafe not where we know that we face risks, but where we do not know what the risks are and how to deal with them." In the same way, Sonia-whose case I mentioned earlierlearned she could trust the drug dealers working in front of her building not to assault her. Such trust remains localized and limited to a habitual situation.

Familiarity and trust are thus complementary ways of reducing complexity (Luhmann 1979): the person who knows everything does not need to trust, and the person who knows nothing cannot rationally afford to (Simmel and Wolff 1950:318). Trust, described as "weak inductive knowledge" by Simmel (quoted by Misztal 1996:141), thus typically emerges out of familiarity, precisely because it is an intermediate position between knowledge and ignorance.

\section{Belonging and attachments}

A second set of consequences of familiarity can be understood in terms of belonging and attachments. The ease described above may translate into belonging through making one feel "at home." However, commuters' practical sense of the train station does not necessarily make them feel at home. Two dimensions appear critical: the type of place and its usage, and the meaning one attributes to the place.

Claude had moved into his apartment six months before I interviewed him. Just like his neighbor Sonia, he quickly discovered that drug dealers worked in front of his building: "At first they often called out to me. Then, they noticed that I live there and they almost ignored me. They know that I live there." Here again, the way familiarity translates into a sense of belonging is a collective achievement more than an individual process. The dealers' civil inattention is understood as an acknowledgment of Claude's "being part of," which provided him with a sense of belonging. What made him feel that way, however, was the fact that he had become familiar to the dealers, not the other way around. This mechanism thus assumes the presence of people to whom we become familiar and who have the opportunity (even involuntarily) to make us aware of it. A residential neighborhood makes this more likely than a transit hub.

Claude's case was also specific in that he was a recent resident of the neighborhood and was eager to make it his home. He therefore appreciated what made him feel like a local. One should not assume, however, that belonging is always desired. With the concept of "elective belonging," Savage, Bagnall, and Longhurst (2005:54) argue that belonging is less a consequence of being an "insider" than a result of considering a place "congruent with one's life story." Moreover, being recognized as "part of" an environment does not mean being recognized as legitimate or accepted. The Simmelian stranger, for instance, is recognized as "being part" of the environment yet remains an outsider (Simmel and Wolff 1950; see also Ahmed 2000). Such a person may belong in a spatial sense but not in a social sense (McLemore 1970). Racist remarks by passers-by and police surveillance remind drug dealers in Geneva that their presence is not legitimate (Felder and Pignolo 2018). 
Depending on one's relationship with a place and its other users, being treated as a familiar stranger can be perceived as a mark of belonging or a mark of indifference and even contempt. In the context of colonialism, Margalit (1998:167) argues, those in positions of power see their "surroundings as familiar scenery that does not demand special examination, since it is assumed that things are the way they are supposed to be." The "self-respecting natives"- as Margalit (1998:167) puts itexperience this attitude as humiliating because, in their opinion, the colonizers should instead feel threatened. What familiarity produces varies according to one's feeling of legitimacy, and therefore according to one's relationship with other people who feel and act familiar. Having a practical sense of place and an understanding of social codes is essential for developing a sense of belonging; yet these factors do not determine belonging.

The notion of attachment offers an alternative way of understanding familiarity. Low and Altman (1992:5) describe attachment to place as "an interplay of affect and emotions, knowledge and beliefs, and behaviors and actions in reference to a place." I will not dive into the definition of this term, but I will insist on its duality. Attachments reassure as much as they constrain. As Hennion (2017:113) notes, states of vulnerability, disability, or addiction also "attach" an individual. What may appear in a positive light as belonging also contains a form of constraint. Just as children are attached to a few places by their parents' rules and their limited autonomy (Chawla 1992), adults are attached to the places of which they have a practical sense. This attachment can be discerned in the performance of routines, by which one may sometimes feel trapped.

\section{Overfamiliarity}

Moving from belonging to attachment opens the door to a more ambivalent reading of familiarity, which goes from "feeling comfortable and 'in the know' to feeling suffocated in a community where one has to adhere to codes because there is no other choice" (Blokland 2017:163). The notion of overfamiliarity suggests an additional level of ambivalence. If becoming familiar relieves the worry of understanding a new environment and finding one's bearings, it also deprives one of the excitement of discovery (Stavo-Debauge 2015).

Although research reveals a preference for the familiar, scholars also point to a contrasting quality of urban environments: unexpectedness or surprise (Lofland 1998:81; Lynch 2005:5). According to Lofland (1973:vii ) - a self-declared "unashamed cityphile"-unexpectedness is one of the urban realm's visual qualities that occasion enjoyment. This does not mean dismissing the familiar. In fact, the unexpected is more likely to be appreciated in a familiar environment. Lynch (2005:56) acknowledges that although we can enjoy mystification, labyrinths, or surprise in an urban environment - as in a house of mirrors - some legibility is crucial:

First, there must be no danger of losing basic form or orientation, of never coming out. The surprise must occur in an overall framework; the confusions must be small regions in a visible whole. Furthermore, the labyrinth or mystery must in itself have some form that can be explored and in time be apprehended. Complete chaos without hint of connection is never pleasurable. 
Unexpectedness can be enjoyed as long as it is not perceived as a threat. This appreciation of surprise and change suggests the possibility of "overfamiliarity." Using a push-pull model, Spierings and van der Velde consider "overfamiliarity" at home as "an emotional reason" to move. However, scholars also note that excessive unfamiliarity discourages mobility (Spierings and van der Velde 2008:501). These authors posit the existence of a "bandwidth of unfamiliarity" corresponding to the degree of unfamiliarity an individual is willing to accept when deciding to move across borders.

Considering the possibility of overfamiliarity highlights the shortcomings of an approach that would overlook situations and aim at discovering "general preferences." In addition to the different relationships to place and varying desire to belong, we may distinguish between periods in life when one seeks to escape from the usual experiences and others when one clings to routine. For example, one can enjoy unexpectedness during a weekend stroll, yet expect a familiar experience during the morning commute to work. Similar distinctions could be made between places where we appreciate being treated as familiar strangers and those where we would welcome more personal attention. These considerations for situational differences are key to studying familiarity empirically.

\section{HOW CAN FAMILIARITY BE OPERATIONALIZED?}

Because "we can know more than we can tell" (Polanyi and Sen 2009), traditional methods such as qualitative interviewing can only explore familiarity to a certain extent. Accessing tacit knowledge and understanding how it is formed and used requires ad hoc methodological approaches such as elicitation techniques. Researchers have used diagrams, diaries, itinerant research techniques, and visual methods. As for the phenomenon of familiar strangers, recent research has approached it through qualitative social network analysis and through statistical analysis of large datasets. In each case, familiarity is operationalized in slightly different ways, reflecting the multiple facets of the concept.

In 1972, Milgram's (2010) psychology students took photographs of people waiting at a train station during a morning commute. One week later, they returned to the same platform, distributed the photos, and asked participants to label anyone they either recognized or to whom they had spoken. This pioneering study of familiar strangers has been replicated. In a plaza of Berkeley's downtown, Paulos and Goodman (2004) found that 78 percent of people surveyed recognized at least one person ( 89 percent in Milgram's experiment). They also confirmed the existence of "sociometric stars," that is, people who are recognized more consistently.

The phenomenon of familiar strangers has gained new attention with the possibilities offered by big data. Based on a dataset consisting of more than 20 million bus trips in Singapore, Sun and colleagues (2013) found a correlation between behavioral regularity and chances of encountering a familiar stranger. Their approach has been replicated using Wi-Fi connection data (Liang, Li, and Zhang 2016) and cellular network data (Zhou, Li, and Yang 2018). These studies show that even 
as they move among the millions of passengers using public transport in a large metropolis, city dwellers regularly meet the same people, which can inject a sense of familiarity into a largely anonymous environment. This familiarity, as shown by a study on the proportion of familiar strangers at bus stops, may have a crime-buffering effect (Zahnow, Zhang, and Corcoran 2020).

Qualitative approaches offer another perspective on familiar strangers. Interaction diaries may shed light on how recurrent encounters influence the perception of places. May and Muir (2015) asked participants to fill out an interaction diary over the course of seven days. Discussing its content with participants revealed "the significance of incidental encounters to the experience of being in geographical place," especially in terms of comfort (May and Muir 2015:4). A challenge, however, is that participants do not necessarily register the sight of a familiar face.

I experimented with a potential workaround to investigate how tenants relate to their neighbors. I presented residents of four buildings with diagrams representing every apartment in their building (Felder 2020). Instead of asking "who do you know in your building," I asked each resident, "what do you know" about the tenants. This revealed that participants knew more than they thought they did. Even those who insisted they did not know anyone in their building had "invisible ties"-also known as "absent ties" or "nodding relationships" (Granovetter 1973:1361) — to neighbors they recognized or "knew about." Here too, some residents were "sociometric stars" or "figures" (Felder 2020). Their existence suggests points of overlapping familiarity, creating commonality between neighbors in the form of shared knowledge.

These approaches focus on familiarity as a feature of interpersonal relationship, but other methods probe people's relationships to the material environment. Lynch's (2005) seminal work popularized the idea that individuals form mental maps of their environment. Asking participants to draw maps of the places where they live is now a method of investigating spatial perception, yet there are limits to this approach when studying familiarity. The first is that mental maps often represent places considered "important," whether liked or disliked. Places of which one has only a practical sense risk appearing simply as lines (what Lynch calls "paths") connecting various nodes. Of course, this signals subsidiary knowledge, and participants could be asked about what the map misses out. However, it does not seem any easier to translate practical meaning into a drawing than into words.

If the aforementioned approaches make it possible to assess the extent of the phenomenon and to evaluate its consequences, to grasp familiarity as an experience of everyday life requires a closer vantage point. Based on participant observation, ethnography appears an ideal method to analyze familiarity and familiarization processes. What Kusenbach (2003:463) calls "natural go-alongs" allow researchers to follow "informants into their familiar environments and track outings they would go on anyway as closely as possible, for instance with respect to the particular day, the time of the day, and the routes of the regular trip." Building on the tradition of ethnographic filmmaking, Pink (2007:248) proposes integrating video into the method of "walking with' . . to represent other people's experiences in movement." 
Such "shadowing" techniques (McDonald 2005) facilitate access to informants' daily experiences as they unfold, making it possible to account for "intersituational variation" (Trouille and Tavory 2019). By contrasting everyday experiences across several situations, one could investigate familiarity as a dynamic process rather than a stable relationship. Focusing on situations of comfort and discomfort promises a richer understanding of what constitutes familiarity. The normal experience of a place perhaps never appears so clearly as when it is disturbed. The emphasis on disruptions goes back to Garfinkel's (1984) "breaching experiments." To study what makes up the "“seen but unnoticed' background of common understandings," Garfinkel (1984:37) suggests researchers "start with familiar scenes and ask what can be done to make trouble" (for a recent example, see Stanley et al. 2020). The simultaneous study of familiarization and defamiliarization processes seems to be the most effective approach to exploring familiarity as a practical sense of place. To do so, methodological creativity appears essential.

\section{CONCLUSIONS}

This article proposed a sociological conceptualization of familiarity as a specific relationship to people and places. I will return to four points that offer avenues for theorizing the empirical investigation.

First, by addressing the causes and effects of familiarity successively, it appears they are entwined. Familiarity is achieved through routine practices, yet these routines ease in familiar environments. Thus, a first conclusion is that thinking in terms of familiarization processes instead of familiarity could be a way to address its workings and avoid describing it as a state of affairs. Familiarization also captures self-reinforcing dynamics at the collective level. I argued that other people behaving routinely in an environment that feels familiar to them is a precondition for one to develop a familiar relationship to that environment. Failing to treat others as familiar strangers or behaving in a way that breaches normal appearances disrupts the collective achievement of familiarity.

Breaches constitute a second promising avenue for researching what is usual and what we take for granted. Sociology has been disproportionately interested in what is unusual or uncommon (e.g., deviances, minorities), but sociologists have also sought to define the norm from the deviant, the unmarked from the marked (Brekhus 1998). Rather than contrasting the norm and the deviant, the usual and the unusual, one could look for the processes through which the taken-for-granted becomes problematic. This opens up avenues for studying everyday life as sequences of familiarization, defamiliarization, and refamiliarization. Future work should analyze the conditions in which a breach can contribute to familiarization - that is, through trial-and-error learning — and those that constitute an insurmountable rupture (Tavory and Fine 2020).

Third, a processual and relational conceptualization of familiarity can complement discussions of the practices that underpin coexistence, particularly in dense and diverse urban environments. Gilroy (2006:xi), for example, refers to "the processes of cohabitation and interaction that have made multiculture an ordinary feature of social life in Britain's urban areas and in postcolonial 
cities elsewhere" as conviviality, adding that it does not imply "the absence of racism or the triumph of tolerance." Could looking at processes of (de)familiarization help account for the dynamic character of such "precarious modes of living together" (Neal et al. 2019:70)?

I believe examining such processes may help us describe how people develop a practical sense of place that incorporates the presence of diverse populations into their "normal experience" and explain why these processes sometimes fail. Moreover, this could help us compare learning to handle the co-presence of strangers (the fate of every city dweller [Lofland 1973]) and what I describe as familiarization, that is, learning about specific people and places in situations we regularly encounter. What does "conviviality" owe to an ability to live among strangers or even to an "ethos of indifference to difference" (Valluvan 2016), and what does it owe to the fact that different strangers end up recognizing each other and learning what to expect from each other?

Fourth, whereas sociologists attach great importance to the places we appropriate materially, symbolically, and emotionally (our place of residence above all), familiarity highlights the relevance of what occurs in between, when we move through public space. Just passing through is not something we can take for granted. It may be a comfortable experience or a troublesome one. By passing through repeatedly, we become visible to others. We may make others feel like they belong or make them feel out of place. The "time in between ... during which people are on their way to live the rest of their lives" deserves more attention, as Blokland and Nast (2014:1144) argue. By treating the "outing" as a starting point for description and inquiry, instead of studying places as if life happened in static containers, DeLand and Trouille (2018) offer ways to move in this direction.

I would like to end with two more normative questions: is familiarity a viable mode of coexistence, and should familiarization of city dwellers be facilitated? As I have described it, familiarity involves a minimal appropriation of places. In theory, it makes room for everyone to develop a "light" sense of home (Duyvendak and Wekker 2016). However, this mode of coexistence has little transformative capacity. This ambivalence has been debated in countless discussions of Simmel's "blasé outlook" and Goffman's "civil inattention": although non-engagement can be seen as a form of "urban care," it can hardly be an "overarching ideal for social interaction between urbanites" (Blonk, Trappenburg, and Bredewold 2021:14). However, the examples presented here (the case of Claude and the one proposed by Margalit) show how context and power relations determine whether being treated as a familiar stranger is a mark of recognition or contempt. It is therefore difficult to determine whether familiarity in itself is a desirable thing or not. What is desirable is a context in which no one would have reason to interpret other people's familiar attitude as a sign of contempt.

This consideration of the ambivalence of familiarity opens up further discussion about whether urban environments should be planned and designed in ways that make familiarization easier. On the one hand, in addition to the literature demonstrating a general preference for the familiar, a growing body of research highlights its significance for older people, especially those suffering from dementia (Brorsson et al. 2011; McGovern 2017; Sandberg et al. 2017). Inclusive urban 
design should thus aim for easily recognizable environments and for incremental, small-scale new developments (Burton and Mitchell 2006:51-63). On the other hand, favoring familiarity and legibility may not only remove the pleasure of surprise and discovery, but it may also hinder certain groups who rely on local familiarity: "Historically," Scott (2008) reminds us, "the relative illegibility to outsiders of some urban neighborhoods ... has provided a vital margin of political safety from control by outside elites." The relational conceptualization of familiarity presented here provides a way out of this dilemma. As a relational and interactional achievement, familiarization rests neither solely on individuals' cognitive and physical capacity (which dementia would threaten, for example), nor on the legibility of the material environment. Could and should cities instead be designed to encourage routine practices and fleeting encounters between familiar strangers?

\section{ACKNOWLEDGMENTS}

I am indebted to Talja Blokland, whose work has been central to the development of these arguments. My thanks go to the four anonymous reviewers at Sociological Theory. Their generous and insightful feedback helped me improve the article significantly. I am also grateful to Garance Clément, Marc-Édouard Schultheiss, Camille Sigg, Joan Stavo-Debauge, and Giacomo Vagni for their comments on earlier versions of this article. I thank Eamon Ali for his language editing service.

\section{FUNDING}

The author(s) disclosed receipt of the following financial support for the research, authorship, and/or publication of this article: I thank the Swiss National Science Foundation (Grant Nos. 155747 and 182295) for the financial support that made this research possible.

\section{ORCID iD}

Maxime Felder https://orcid.org/0000-0002-1056-9255

\section{NOTE}

1. Around the year 2000, an amnesic patient gave neuroscientists the opportunity to observe the biological dimension of this embodied sense of place. Even though parts of his brain essential for memory were dysfunctional, the patient was still able to find his way around in familiar neighborhoods (Rosenbaum et al. 2000; Teng and Squire 1999). 


\section{REFERENCES}

Ahmed, Sara. 2000. Strange Encounters: Embodied Others in Post-Coloniality. London: Routledge.

Ahmed, Sara. 2007. “A Phenomenology of Whiteness." Feminist Theory 8(2):149-68. doi: $10.1177 / 1464700107078139$.

Amin, Ash. 2008. "Collective Culture and Urban Public Space." City 12(1):5-24. doi: $10.1080 / 13604810801933495$.

Anderson, Elijah. 1990. Streetwise: Race, Class, and Change in an Urban Community. Chicago: University of Chicago Press.

Anderson, Elijah. 2000. Code of the Street: Decency, Violence, and the Moral Life of the Inner City. New York: W. W. Norton \& Company.

Blokland, Talja. 2003. Urban Bonds. Cambridge, UK: Polity.

Blokland, Talja. 2011. “'Even When I See the Real Scoundrel around Here, I Don't Feel Unsafe." Pp. 173-96 in Die Besonderheit des Städtischen. Wiesbaden: VS Verlag für Sozialwissenschaften.

Blokland, Talja. 2017. Community as Urban Practice. Cambridge, UK: Polity.

Blokland, Talja, and Julia Nast. 2014. "From Public Familiarity to Comfort Zone: The Relevance of Absent Ties for Belonging in Berlin Mixed Neighbourhoods." International Journal of Urban and Regional Research 38(4):1142-11 59. doi: 10.1111/1468-2427.12126.

Blonk, Laurine, Margo Trappenburg, and Femmianne Bredewold. 2021. “I Can't Just Go up to a Person to Ask What's Going on.' How Dutch Urbanites' Accounts of Non-Engagement Enhance Our Understanding of Urban Care.” Urban Studies 004209802199701. doi: $10.1177 / 0042098021997013$.

Brekhus, Wayne. 1998. "A Sociology of the Unmarked: Redirecting Our Focus.” Sociological Theory 16(1):34-51. doi: 10.1111/0735-2751.00041.

Brorsson, Anna, Annika Öhman, Stefan Lundberg, and Louise Nygård. 2011. "Accessibility in Public Space as Perceived by People with Alzheimer's Disease.” Dementia 10(4):587-602. doi: 10.1177/1471301211415314.

Burns, Victoria F., Jean-Pierre Lavoie, and Damaris Rose. 2012. "Revisiting the Role of Neighbourhood Change in Social Exclusion and Inclusion of Older People." Journal of Aging Research 2012(8b):1-12. doi: 10.1155/2012/148287.

Burton, Elizabeth, and Lynne Mitchell. 2006. Inclusive Urban Design: Streets for Life. Amsterdam: Architectural Press.

Casey, Edward S. 2000. Remembering: A Phenomenological Study. 2nd ed. Bloomington: Indiana University Press.

Casey, Edward S. 2009. Getting Back into Place: Toward a Renewed Understanding of the Place-World. 2nd ed. Bloomington: Indiana University Press.

Chawla, Louise. 1992. "Childhood Place Attachments." Pp. 63-86 in Place Attachment, edited 
by I. Altman and S. M. Low. Boston, MA: Springer US.

Cogger, Rachel. 2016. “Tuning in and out of Place.” Pp. 120-37 in Place and Placelessness Revisited, edited by R. Freestone and E. Liu. New York: Routledge.

DeLand, Michael, and David Trouille. 2018. "Going Out: A Sociology of Public Outings." Sociological Theory 36(1):27-47. doi: 10.1177/0735275118759149.

Duyvendak, Jan Willem and Fenneke Wekker. 2016. "2. At home in the city?” Pp. 22-30 in Urban Europe, edited by G. Marini. Amsterdam: Amsterdam University Press. https://doi.org/10.1515/9789048535811-003

Eric Paulos, and Elizabeth Goodman. 2004. "The Familiar Stranger: Anxiety, Comfort, and Play in Public Places." Pp. 223-230 in Proceedings of the SIGCHI Conference on Human Factors in Computing Systems. New York: Association for Computing Machinery. https://doi.org/10.1145/985692.985721

Felder, Maxime. 2016. "La Diversité Sur Le Palier. Catégorisations Ordinaires d'un Voisinage Hétérogène à Genève.” Lien Social et Politiques (77):220-39. doi: 10.7202/1037910ar.

Felder, Maxime. 2019. "Who Are the Strangers? Neighbour Relations in Socially and Ethnically Heterogeneous Residential Buildings in Geneva." Pp. 24-25 in DIVERCITIES:

Understanding Super Diversity in Deprived and Mixed Neigbourhoods, edited by S. Oosterlynck, G. Verschraegen, and R. van Kempen. Bristol, UK: Policy Press.

Felder, Maxime. 2020. "Strong, Weak and Invisible Ties: A Relational Perspective on Urban Coexistence.” Sociology 54(4):675-92. doi: 10.1177/0038038519895938.

Felder, Maxime, and Loïc Pignolo. 2018. ““Je Préfère Les Dealers à Une Rue Déserte’: Coexistence et Familiarisation En Milieu Urbain.” Sociologie 9(1):1-18.

Fischer, Claude. 1982. To Dwell among Friends: Personal Networks in Town and City. Chicago: University of Chicago Press.

Gallagher, Shaun, and Dan Zahavi. 2020. The Phenomenological Mind. New York: Routledge.

Garfinkel, Harold. 1984. Studies in Ethnomethodology. Cambridge, UK: Polity.

Gilroy, Paul. 2006. After Empire: Melancholia or Convivial Culture? Reprinted. Abingdon, UK: Routledge.

Goffman, Erving. 1971. Relations in Public: Microstudies of the Public Order. New York: Basic Books.

Granovetter, Mark. 1973. "The Strength of Weak Ties.” American Journal of Sociology 78(6):1360-80.

Haapala, Arto. 2005. "On the Aesthetics of the Everyday: Familiarity, Strangeness, and the Meaning of Place.” Pp. 39-55 in The Aesthetics of Everyday Life. New York: Columbia University Press.

Heidegger, Martin. 2010 [1927]. Being and Time. Albany: State University of New York Press.

Hennion, Antoine. 2017. "Attachments, You Say? ... How a Concept Collectively Emerges in One Research Group.” Journal of Cultural Economy 10(1):112-21. doi:

10.1080/17530350.2016.1260629. 
Henshaw, Victoria. 2014. Urban Smellscapes: Understanding and Designing City Smell Environments. New York: Routledge.

Kumar, Krishan, and Ekaterina Makarova. 2008. "The Portable Home: The Domestication of Public Space.” Sociological Theory 26(4):324-43. doi: 10.1111/j.1467-9558.2008.00332.x.

Kusenbach, Margarethe. 2003. "Street Phenomenology: The Go-Along as Ethnographic Research Tool.” Ethnography 4(3):455-85. doi: 10.1177/146613810343007.

Lee, A. Y. 2001. "The Mere Exposure Effect: An Uncertainty Reduction Explanation Revisited." Personality and Social Psychology Bulletin 27(10):1255-66.

Lewis, J. David, and Andrew Weigert. 1985. "Trust as a Social Reality." Social Forces 63(4):967. doi: 10.2307/2578601.

Liang, Di, Xiang Li, and Yi-Qing Zhang. 2016. "Identifying Familiar Strangers in Human Encounter Networks.” EPL (Europhysics Letters) 116(1):18006. doi: 10.1209/02955075/116/18006.

Lofland, Lyn. 1973. A World of Strangers: Order and Action in Urban Public Space. New York: Basic Books.

Lofland, Lyn. 1998. The Public Realm: Exploring the City's Quintessential Social Territory. Hawthorne, NY: Aldine de Gruyter.

Low, Setha M., and Irwin Altman. 1992. "Place Attachment." Pp. 1-12 in Place Attachment, edited by I. Altman and S. M. Low. Boston, MA: Springer US.

Luhmann, Niklas. 1979. Trust and Power. Chichester, UK: John Wiley \& Sons.

Luhmann, Niklas. 2000. "Familiarity, Confidence, Trust: Problems and Alternatives." Trust: Making and Breaking Cooperative Relations 6(1):94-107.

Lynch, Kevin. 2005. The Image of the City. Cambridge, MA: MIT Press.

Margalit, Avishai. 1998. The Decent Society. Cambridge, MA: Harvard University Press.

Marsden, P. V., and K. E. Campbell. 2012. "Reflections on Conceptualizing and Measuring Tie Strength." Social Forces 91(1):17-23. doi: 10.1093/sf/sos112.

May, Vanessa, and Stewart Muir. 2015. "Everyday Belonging and Ageing: Place and Generational Change.” Sociological Research Online 20(1):72-82. doi: 10.5153/sro.3555.

McDonald, Seonaidh. 2005. "Studying Actions in Context: A Qualitative Shadowing Method for Organizational Research." Qualitative Research 5(4):455-73. doi:

$10.1177 / 1468794105056923$.

McFarlane, Colin. 2011. Learning the City: Knowledge and Translocal Assemblage. 1st ed. Malden, MA: Wiley-Blackwell.

McGovern, Justine. 2017. "Capturing the Significance of Place in the Lived Experience of Dementia.” Qualitative Social Work 16(5):664-79. doi: 10.1177/1473325016638424.

McLemore, S. Dale. 1970. "Simmel's 'Stranger': A Critique of the Concept." The Pacific Sociological Review 13(2):86-94. doi: 10.2307/1388311.

Merleau-Ponty, Maurice. 2005. Phenomenology of Perception. London: Routledge. 
Milgram, Stanley. 2010. The Individual in a Social World: Essays and Experiments. London: Pinter \& Martin.

Misztal, Barbara A. 1996. Trust in Modern Societies: The Search for the Bases of Social Order. Cambridge, UK: Polity Press.

Misztal, Barbara A. 2015. Multiple Normalities: Making Sense of Ways of Living. New York: Palgrave Macmillan.

Neal, Sarah, Katy Bennett, Allan Cochrane, and Giles Mohan. 2019. "Community and Conviviality? Informal Social Life in Multicultural Places.” Sociology 53(1):69-86. doi: $10.1177 / 0038038518763518$.

Pink, Sarah. 2007. "Walking with Video.” Visual Studies 22(3):240-52. doi: $10.1080 / 14725860701657142$.

Polanyi, Michael. 1962. "Tacit Knowing: Its Bearing on Some Problems of Philosophy.” Reviews of Modern Physics 34(4):601-16. doi: 10.1103/RevModPhys.34.601.

Polanyi, Michael, and Amartya Sen. 2009. The Tacit Dimension. Chicago: University of Chicago Press.

Rawls, Anne Warfield. 1987. "The Interaction Order Sui Generis: Goffman's Contribution to Social Theory." Sociological Theory 5(2):136. doi: 10.2307/201935.

Relph, Edward. 2008. Place and Placelessness. Reprinted. London: Pion Limited.

Riom, Loïc, Cornelia Hummel, and Claudine Burton-Jeangros. 2018. "« Mon quartier a changé un peu, mais c'est moi qui ai aussi beaucoup changé ». Habiter la ville et y vieillir." Métropoles (23). doi: 10.4000/metropoles.6449.

Rodgers, Dennis. 2020. "The Drugs Consensus: The Spatial Policing of Dealing and Consumption in Geneva, Switzerland." City \& Society ciso.12368. doi: 10.1111/ciso.12368.

Rosenbaum, R. Shayna, Sandra Priselac, Stefan Köhler, Sandra E. Black, Fuqiang Gao, Lynn Nadel, and Morris Moscovitch. 2000. "Remote Spatial Memory in an Amnesic Person with Extensive Bilateral Hippocampal Lesions." Nature Neuroscience 3(10):1044-48. doi: $10.1038 / 79867$.

Rosenblum, Nancy. 2016. Good Neighbors : The Democracy of Everyday Life in America. Princeton, NJ: Princeton University Press.

Sandberg, Linda, Lena Rosenberg, Per-Olof Sandman, and Lena Borell. 2017. "Risks in Situations That Are Experienced as Unfamiliar and Confusing - the Perspective of Persons with Dementia." Dementia 16(4):471-85. doi: 10.1177/1471301215603836.

Savage, Michael, Gaynor Bagnall, and Brian Longhurst. 2005. Globalization and Belonging. London: SAGE.

Schütz, Alfred, and Thomas Luckmann. 1973. The Structures of the Life-World. Vol. 1. London: Heinemann.

Scott, James C. 2008. Seeing like a State: How Certain Schemes to Improve the Human Condition Have Failed. Nachdr. New Haven, CT: Yale University Press.

Shamai, Shmuel, and Zinaida Ilatov. 2005. "Measuring Sense of Place: Methodological Aspects." 
Tijdschrift Voor Economische En Sociale Geografie 96(5):467-76. doi: 10.1111/j.14679663.2005.00479.x.

Shove, Elizabeth, Mika Pantzar, and Matt Watson. 2012. The Dynamics of Social Practice: Everyday Life and How It Changes. Los Angeles, CA: SAGE.

Simmel, Georg, and Kurt H. Wolff. 1950. The Sociology of Georg Simmel. Glencoe, IL: Free Press.

Speelman, Craig P., and Kim Kirsner. 2005. Beyond the Learning Curve: The Construction of Mind. Oxford, UK: Oxford University Press.

Spierings, Bas, and van der Velde, Martin. 2008. "Shopping, Borders and Unfamiliarity: Consumer Mobility in Europe." Tijdschrift Voor Economische En Sociale Geografie 99(4):497-505.

Stanley, Steven, Robin James Smith, Eleanor Ford, and Joshua Jones. 2020. "Making Something out of Nothing: Breaching Everyday Life by Standing Still in a Public Place." The Sociological Review 68(6):1250-72. doi: 10.1177/0038026120940616.

Stavo-Debauge, Joan. 2015. "De The Stranger d'Alfred Schütz Au Cas Agnès d'Harold Garfinkel." SociologieS. https://journals.openedition.org/sociologies/4955.

Sun, Lijun, Kay W. Axhausen, Der-Horng Lee, and Xianfeng Huang. 2013. "Understanding Metropolitan Patterns of Daily Encounters." Proceedings of the National Academy of Sciences 110(34):13774-79. doi: 10.1073/pnas.1306440110.

Sztompka, Piotr. 1999. Trust: A Sociological Theory. Cambridge, UK: Cambridge University Press.

Tavory, Iddo, and Gary Alan Fine. 2020. "Disruption and the Theory of the Interaction Order." Theory and Society 49(3):365-85. doi: 10.1007/s11186-020-09384-3.

Teng, Edmond, and Larry R. Squire. 1999. "Memory for Places Learned Long Ago Is Intact after Hippocampal Damage." Nature 400(6745):675-77. doi: 10.1038/23276.

Thévenot, Laurent. 1994. "Le Régime de Familiarité. Des Choses En Personne." Genèses 17:72101.

Thévenot, Laurent. 2001. "Pragmatic Regimes Governing the Engagement with the World." Pp. 56-73 in The Practice Turn in Contemporary Theory, edited by T. R. Schatzki, K. KnorrCetina, and E. von Savigny. London: Routledge.

Thévenot, Laurent. 2007. "The Plurality of Cognitive Formats and Engagements Moving between the Familiar and the Public." European Journal of Social Theory 10(3):409-23.

Timmermans, Stefan, and Iddo Tavory. 2012. "Theory Construction in Qualitative Research: From Grounded Theory to Abductive Analysis." Sociological Theory 30(3):167-86. doi: $10.1177 / 0735275112457914$.

Titchener, Edward Bradford. 1914. A Text-Book of Psychology. New York: MacMillan.

Trouille, David, and Iddo Tavory. 2019. "Shadowing: Warrants for Intersituational Variation in Ethnography." Sociological Methods \& Research 48(3):534-60. doi:

$10.1177 / 0049124115626171$. 


\section{--- Preprint ---}

Vagni, Giacomo, and Benjamin Cornwell. 2018. "Patterns of Everyday Activities across Social Contexts." Proceedings of the National Academy of Sciences 115(24):6183-88. doi: 10.1073/pnas.1718020115.

Valluvan, Sivamohan. 2016. "Conviviality and Multiculture: A Post-Integration Sociology of Multi-Ethnic Interaction.” YOUNG 24(3):204-21. doi: 10.1177/1103308815624061.

Ward, Richard, Kirstein Rummery, Elzana Odzakovic, Kainde Manji, Agneta Kullberg, John Keady, Andrew Clark, and Sarah Campbell. 2021. "Beyond the Shrinking World: Dementia, Localisation and Neighbourhood." Ageing and Society:1-22. doi: 10.1017/S0144686X21000350.

Whyte, William. 1943. Street Corner Society: The Social Structure of an Italian Slum. Chicago: The University of Chicago Press.

Willen, Sarah S. 2007. “Toward a Critical Phenomenology of 'Illegality': State Power, Criminalization, and Abjectivity among Undocumented Migrant Workers in Tel Aviv, Israel.” International Migration 45(3):8-38. doi: 10.1111/j.1468-2435.2007.00409.x.

Zahnow, Renee, Min Zhang, and Jonathan Corcoran. 2020. "The Girl on the Bus: Familiar Faces in Daily Travel and Their Implications for Crime Protection." Annals of the American Association of Geographers 111(5):1367-1384. doi: 10.1080/24694452.2020.1828026.

Zajonc, Robert B. 1968. “Attitudinal Effects of Mere Exposure.” Journal of Personality and Social Psychology 9(2):1-27. doi: 10.1037/h0025848.

Zhou, Jiangping, Ying Li, and Yuling Yang. 2018. "Familiar Strangers: Visualising Potential Metro Encounters in Beijing." Environment and Planning A: Economy and Space 50(2):262-65. doi: 10.1177/0308518X17745874. 